\title{
fifeet of Cultivar and Crown Size on Yield and Quality of Strawberry Bare Root Plants in Sicily
}

Anna, G. Caracciolo, A. Moncada and F. Vetrano

thartimento di Agronomia Ambientale e Territoriale Sez. di Orticoltura e Floricoltura wersità degli Studi di Palermo

aternwords: 'Candonga', 'Nora', starch content, crown diameter

\section{fisatract}

In the southern regions of Mediterranean areas the plantations with fresh

(winter planting system) have almost completely replaced those with cold plants (summer planting system). Particularly, fresh bare root plants ced in high elevation nurseries located in Spain and Poland and, in perimental phase, in the southern of Italy (in the mountains of Sicily, Calabria, assilicata) are the most used. Such type of plant usually has a crown diameter from iii) $14 \mathrm{~mm}$, but the smallest plants should be $(<8 \mathrm{~mm})$ discarded in phase of ettertion and packing. Objective of this study was to investigate the influence of the witifiterent crown diameter on the earliness, productivity and quality of two new anditivars of strawberry. The research was carried out in 2007/08 in the experimental idits located in Palermo. Three typologies of fresh bare-root plants (small plants: maren diameter 6-8 mm; medium plants: 8.1-11 mm and large plants 11.1-14 mm) and two cultivars ('Candonga' and 'Nora') were compared. The experimental design us a split-plot with 3 replication and individual experimental plot of $4.6 \mathrm{~m}^{2}$. The mation was established the $22^{\text {nd }}$ of October in a plastic greenhouse of $600 \mathrm{~m}^{2}$, on (inin-row beds and at a plants density of 9.1 plant $/ \mathrm{m}^{2}$. The production started in wuary and finished in May. The medium plants (crown diameter 8.1-11 mm) were airlier than the others types. The marketable production during the whole hamesting period was influenced by crown diameter. Large and medium plants (16rawn diameter 8.1-14 mm) produced more than small plants (crown diameter 6-8 (respectively 590 and $551 \mathrm{~g} / \mathrm{plant}$ ). 'Candonga' (586.8 g/plant) produced more inan 'Nora' (567.9 g/plant). The average strawberry weight wasn't statistically itifienced by the typology of plant but by the cultivar; 'Candonga' produced the ingest fruits. The crown diameter of fresh plants influenced earliness and roductivity of strawberries. To ensure high production it should be use medium and large fresh plant with a crown diameter from 8.1 to $14 \mathrm{~mm}$.

\section{TRODUCTION}

In Sicily the largest strawberry production area is located near Marsala (Trapani) covers about 380 hectares. The productivity increase of cold stored plants is carried ut by a loss of earliness and quality of the fruit (size, shape) (Hennion et al., 1997). In the last decade, cold stored plant have been almost completely replaced by fresh bare root plant which require less management (with these plant can be avoid the old runner removal) and less input (as water and fertilizer), which give more interesting performance because of a very long fruiting season (from December to May) and an earlier and greater total fruit production (Moncada et al., 2009). For every strawberry cultivation system, several factors are cited to justify that successful production depends on a supply of high quality plants (Johnson et al., 2005): little plants will perform poorly in the production field, early modification in the first vegetative phase can impact fruit yield, strong and robust plants establish more quickly and easily. It was verified that plant size is important because flower number increases with increased daughter plant crown diameter (Jemmali and Boxus, 1993) and that crown diameter is linked not only to size and number of flower trusses but to the inflorescence initiation too (Mason, 1987). Fresh bare root plants are produced in nursery field where variability in plant size can occur because of the 
developmental differences in vegetatively propagated daughter plants and because of the digging process that can destroy part of the roots and reduce the total starch content. This variability has important implications for fruit production (Bish et al., 2003) because much of the variation has been just attributed to the carbohydrates content in the plant crown that represents an important reservoir of starch. It has been reported that an increase in fruit yield have been obtained in plants with high initial starch levels in the roots (Macias-Rodriguez et al., 2002; Wang and Camp, 2000; Maas, 1986); even strawberry number and average fruit weight seem to be positively correlated to crown size (Le Mière et al., 1998). However, the optimum transplant size has not jet been elucidated (Johnson et al., 2005); Popenoe and Swartz (1985) suggested that the importance of yield components depends on the cultivar and the production system while other authors indicate that the optimum crown size has to be determined for each individual cultivar (Chercuitte et al., 1991). Objective of this study was to investigate the influence of the different crown diameter on the earliness, productivity and quality of two new cultivars of strawberry.

\section{MATERIALS AND METHODS}

The research was carried out in 2007-2008 on the experimental farm of the Horticultural and Floricultural Branch of the Department SAGA of the University of Palermo. Two cultivars ('Candonga' and 'Nora') and three crown size were compared (small plants: crown diameter 6-8 mm; medium plants: crown diameter $8.1-11 \mathrm{~mm}$; large plants: crown diameter $11.1-14 \mathrm{~mm}$ ). Plants were obtained from a high elevation nursery located at Cammarata ( $800 \mathrm{~m}$ of altitude), where mother plants produced runners which remained hanging above the ground. At the required planting date, fresh bare root plants were rooted out and transplanted in a loam soil, in a unheated greenhouse-tunnel of 600 $\mathrm{m}^{2}$ covered with polyethylene, in a split plot design with 3 replication and individual experimental plot of $4.6 \mathrm{~m}^{2}$. It was adopted the typically cultivation technique, according to the standard growing system for the area (D'Anna et al., 2007): in August the soil was ploughed and disced, then it was improved with the addition of 100 t/ha of exhausted grape marc before mulching. Before transplanting, $50 \mathrm{~kg} / \mathrm{ha}$ of $\mathrm{N}, 150 \mathrm{~kg} / \mathrm{ha}$ of $\mathrm{P}_{2} \mathrm{O}_{5}, 150$ $\mathrm{kg} / \mathrm{ha}$ of $\mathrm{K}_{2} \mathrm{O}$ and $60 \mathrm{~kg} / \mathrm{ha}$ of $\mathrm{S}$ were added. Then, a microirrigation system was placed upon the soil, arranged with raised bed $(40 \mathrm{~cm})$, and used for drip fumigation with chloropicrin +1 ,3dichloropropene, 30 days before transplant. Plantation was established the $22^{\text {nd }}$ of October on two-row beds and at a plants density of $9.1 \mathrm{plant} / \mathrm{m}^{2}$. Greenhouse was covered with EVA in the in the $2^{\text {nd }}$ decade of November. After transplant, fertilization was conducted by fertirrigation; on the whole, $230 \mathrm{~kg} / \mathrm{ha}$ of $\mathrm{N}, 80 \mathrm{~kg} / \mathrm{ha}$ of $\mathrm{P}_{2} \mathrm{O}_{5}$ and $170 \mathrm{~kg} / \mathrm{ha}$ of $\mathrm{K}_{2} \mathrm{O}$ were given. Fruit were harvested twice a week for yield and quality evaluation. Data were collected on marketable and unmarketable fruit yield. average fruit weight, fruit hardness and solid soluble contents. The fruit flesh firmness was measured with a Chantillon penetometer (with a $\mathrm{mm} 6$ plunger) and the solid soluble content $\left({ }^{\circ}\right.$ Brix) using a digital refractometer. Data were statistically analysed by analysis of variance and mean separation was performed by Duncan's multiple range test.

\section{RESULTS AND DISCUSSION}

The production started in January (only one harvest) and ended in the last ten days of May, although all the plants produced very little until February. In the first month of harvest, no statistically significant differences were found among the cultivars that produced on average $82.8 \mathrm{~g} / \mathrm{plant}$. Regarding crown size the maximum yield was obtained by plant with a diameter of $8.1-11 \mathrm{~mm}(87.6 \mathrm{~g} / \mathrm{plant})$, although not differing significantly from plants of $11.1-14 \mathrm{~mm}$ crown size $(85.5 \mathrm{~g} / \mathrm{plant})$ (Table 1$)$. The highest yield was reached by the plants of 'Nora' with crown size of $8.1-11 \mathrm{~mm}(75.7 \mathrm{~g} / \mathrm{plant})$ followed by the plants of $11.1-14 \mathrm{~mm}$ (68.1 g/plant) (Fig. 1). No statistically significant differences were found among fruit production in March, both regarding the cultivars and the crown size. The results indicate the same trend during April: no differences were observed between the cultivars or between plant with different crown size. 'Candonga' plants of 

produced fruit with the highest average weight above all at the beginning and at the as of the productive cycle. Also the qualitative aspects seem to be more dependents an cultivars. In conclusion, strawberry yield and quality are highly influenced combination of several factors such genotype, crown size, but even geaciannas agricultural techniques and plant typology; so, considering only the crown diamteres as the basis for good production would be an over mistake.

\section{Literature Cited}

Bish, E.B., Cantliffe, D.J. and Chandler, C.K. 2003. Plantet size affects growertit development of strawberry plug transplants. Proc. Fla. State Hort. Soc. 116:105-13t

Chercuitte, L., Sullivan, Y.A., Desjardins, Y.D. and Bedard, R. 1991. Yield potemiani a vegetative growth of summer-planted strawberry. Journal of the American Saciess Horticultural Science 116:930-936.

D'Anna, F., Moncada, A., Prinzivalli, C. and Caracciolo, G. 2007. Sicilia: meglio usann piante fresche ma dipende dalla varietà impiegata. Rivista di Frutticoluma an ortofloricoltura 4:26-33.

Hennion, B., Scupp, J. and Longuessere, J. 1997. 'Fraisimotte ${ }^{\circledR}$ ': a strawberry pilum mas developed by CIREF in France. Acta Hort. 439:469-474.

Jemmali, A. and Boxus, P. 1993. Early estimation of strawberry floral intensity ans: improvement under cold greenhouse. Acta Hort. 348:357-360.

Johnson, C., Raiford, T. and Whitley, K. 2005. Initial crown diameter of transinse influences marketable yield components of two strawberry cultivars in anminat production system. International Journal of Fruit Science 5:23-29.

Le Mière, P., Hadley, P., Darby, J. and Battey, N. 1998. The effect eff ansm environment, planting date and crown size on growth, development and anes Fragaria $\mathrm{x}$ ananassa Duch. cv Elsanta. J. Hort. Sci. Biotechnol. 73:786-795.

Maas, J. 1986. Photoperiod and temperature effects on starch accumulation in stimanimerem roots. Adv. Strawberry Prod. 5:22-24.

Macias-Rodriguez, L., Quero, E. and Lòpez, M.G. 2002. Carbohydrate difteremestrawberry crowns and fruit (Fragaria x ananassa) during plant develagnman Agric. Food Chem. 50:3317-3321.

Mason, D.T. 1987. Effect of initial plant size on the growth and croprementing strawberry (Fragaria x ananassa Duch.). Crop Res. (Hort. Res.) 27:31-47.

Moncada, A., Caracciolo, G., Prinzivalli, C., Vetrano, F. and D'Anna, F. 2000 dell'epoca di trapianto di piante fresche a radice nuda di fragole prodotse VII Convegno nazionale 'La fragola: presente e futuro', Marsala (TP) 25-27 iemtans

Popenoe, J. and Swartz, H.J. 1985. Yield component comparison of straw hem grown in various cultural systems. Adv. Strawberry Prod. 4:10-14.

Wang, S. and Camp, M. 2000. Temperatures after bloom affect plant grometib anis test quality of strawberry. Sci. Hort. 85:183-199. 



\section{Figures}

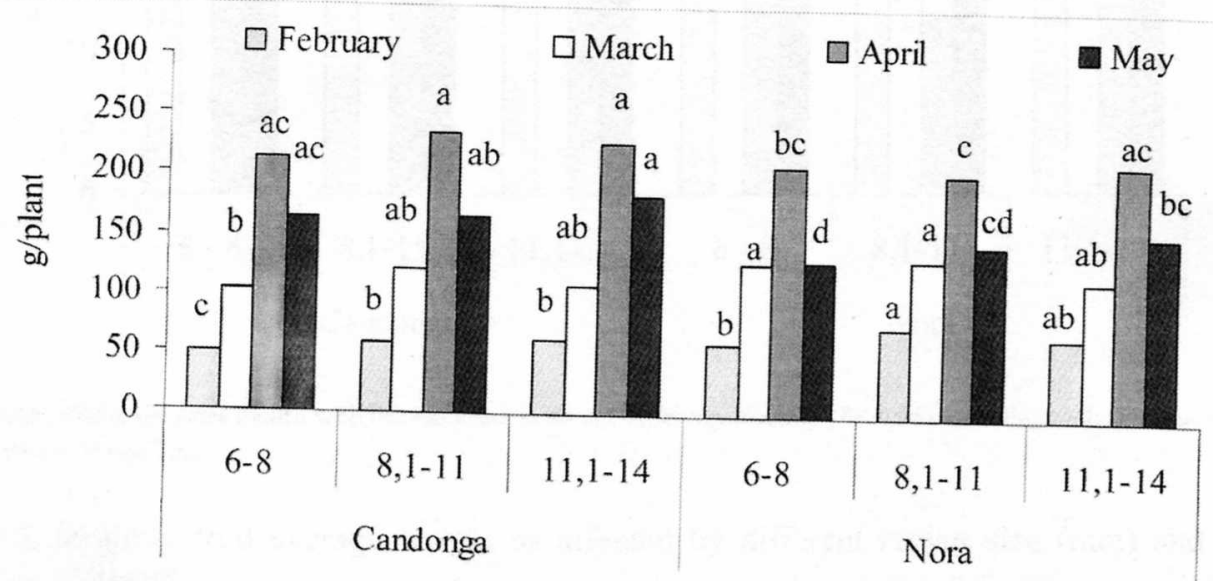

Means within the same month with the same letters do not differ significantly $(\mathrm{P}<0.05)$ according to the Duncan's
Multiple Range Test

Fig. 1. Monthly strawberry yield as affected by different crown size $(\mathrm{mm})$ and by

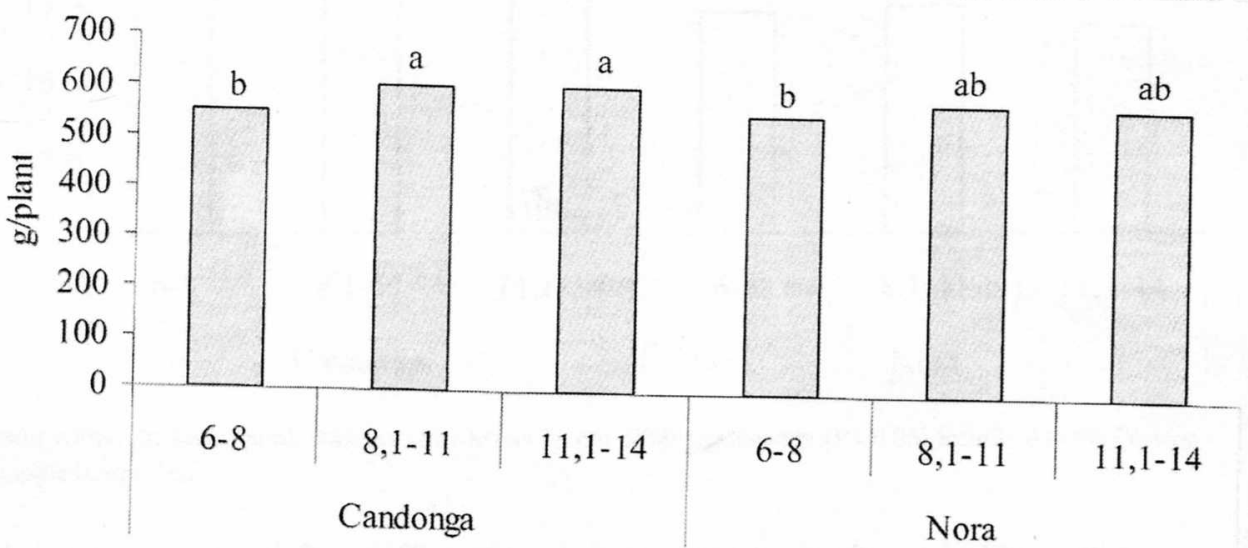

Means within the same month with the same letters do not differ significantly $(P<0.05)$ according to the Duncan's
Multiple Range Test

Fig. 2. Total yield as affected by different crown size ( $\mathrm{mm})$ and by cultivars. 


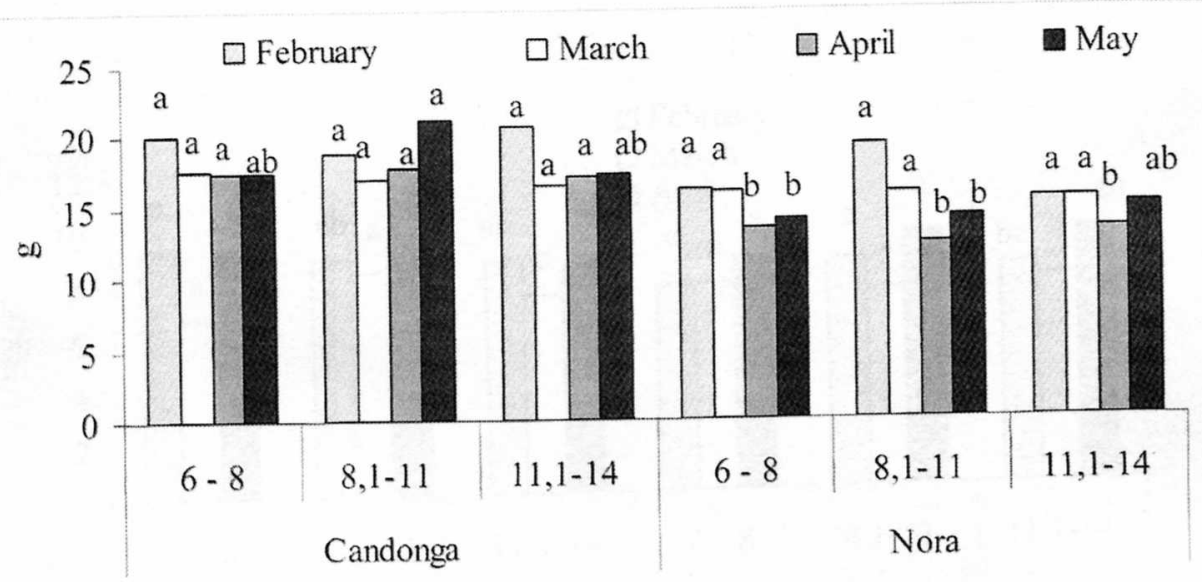

Means within the same month with the same letters do not differ significantly $(P<0.05)$ according to the Duncan's Multiple Range Test

Fig. 3. Monthly fruit average weight as affected by different crown size $(\mathrm{mm})$ and by cultivars.

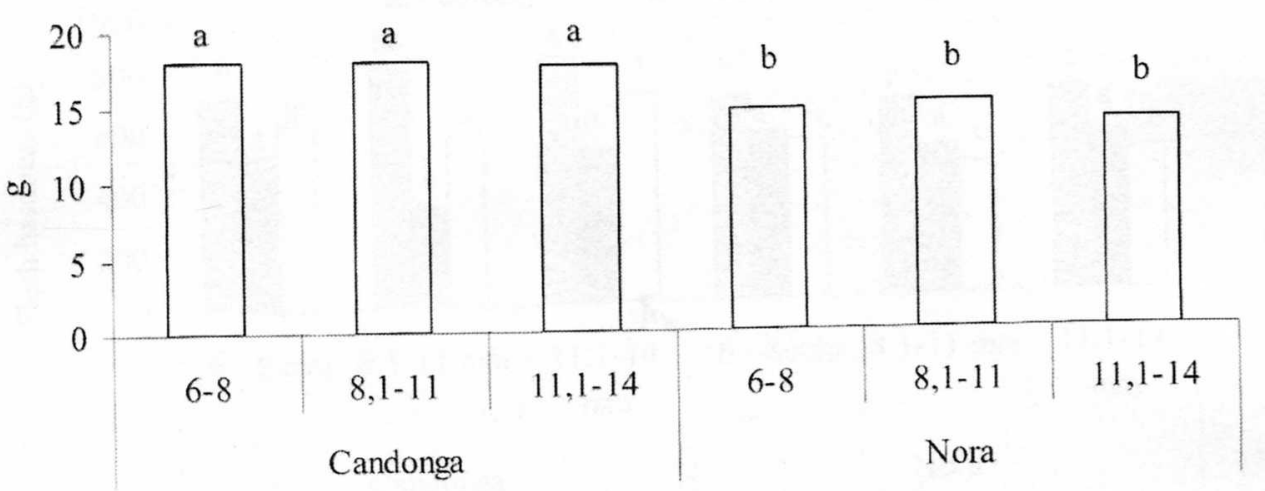

Means within the same month with the same letters do not differ significantly $(P<0.05)$ according to the Duncan's Multiple Range Test

Fig. 4. Fruit average weight as affected by different crown size ( $\mathrm{mm}$ ) and by cultivars. 


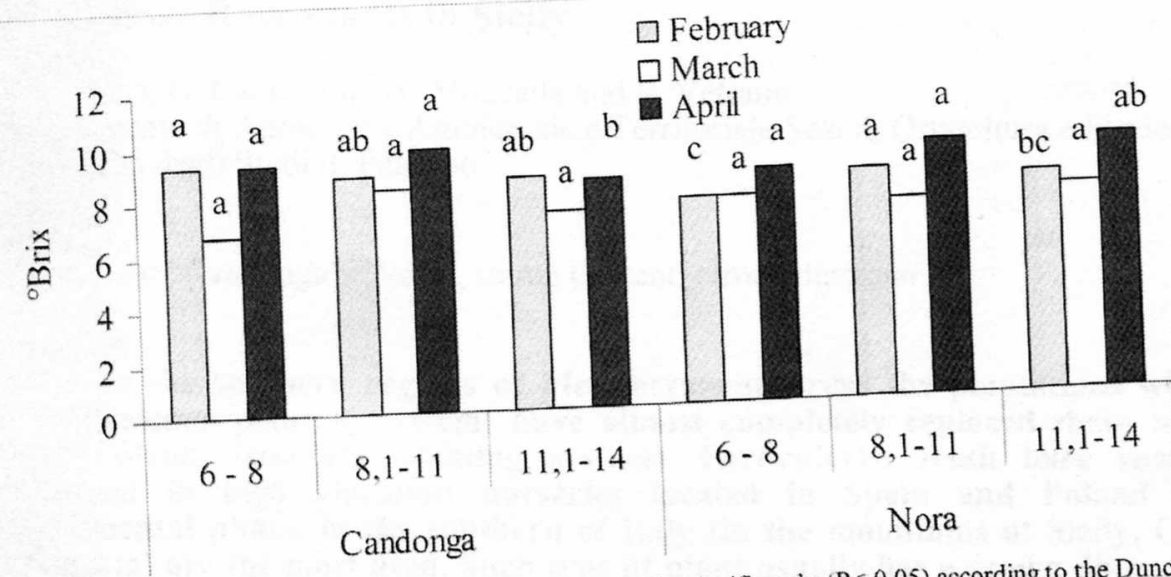

Use

Garc

Ch. L:

Unive

Schor

Depan

Volos

Greec

Keyи

Abst

shapı

to $\mathrm{ph}$

on q1

sumi

area

Multiple Range Test

shad

alrea

Fig. 5. Monthly fruit solid soluble contents as affected by different crown size ( $\mathrm{mm}$ ) and by cultivars.

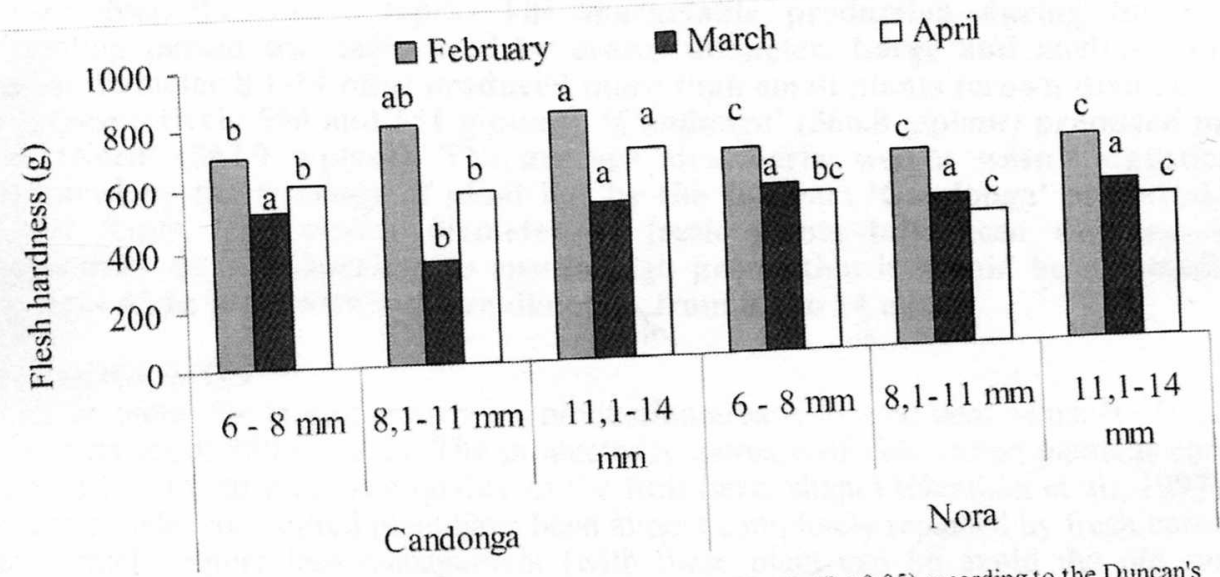

greel

deve

mea:

nets

cond

shad

unds

grov

of th

INT

whit

high

defo

culti

dece

envi

adv:

diffi

This

pho

sper

and

Means within the sat
Multiple Range Test

Fig. 6. Monthly fruit flesh hardness as affected by different crown size $(\mathrm{mm})$ and by cultivars. 